\title{
Las humanidades de hoy en la encrucijada posthumana*
}

\author{
Verónica Araiza Díaz
}

Los cambios complejos y acelerados de las últimas décadas han sido un reto intelectual para las humanidades y las ciencias sociales, disciplinas encargadas de explicar los fenómenos socioculturales. La revolución tecnológica de la información, el despliegue del capitalismo cognitivo, extractivista y de hiperconsumo han moldeado nuestras formas de vida en modos que no alcanzamos a registrar a cabalidad. Aunado a esto, la crisis ambiental de grandes dimensiones en la que nos encontramos -y que guarda una relación estrecha con el sistema económico-, supone un momento límite en la historia de la humanidad, que ha encontrado nombre en el neologismo Antropoceno.

Se trata originalmente de un término de las ciencias duras, en particular de la geología, propuesto para referir una nueva era geológica, caracterizada por la acción del ser humano y su posible capacidad de modificar la biósfera. En dicho campo científico no hay un acuerdo al respecto, por lo que no es un término avalado por la comunidad correspondiente; por el contrario, en las humanidades, y en menor medida en las ciencias sociales, podríamos decir que se ha viralizado, se ha convertido en un meme (Braidotti, 2019). Aunque se han propuesto otros conceptos para acusar mayor precisión del fenómeno, como es el caso de Capitaloceno, que hace referencia al sistema económico como responsable de la devastación ambiental, el término Antropoceno es el más utilizado y ha fungido como detonador de una vasta producción de conocimiento en nuestros campos, centrada en el abordaje, en modos más originales y vanguardistas, de los fenómenos de los años recientes que conforman el paisaje actual del capitalismo.

En este contexto, Rosi Braidotti, filósofa feminista italo-australiana, heredera de la escuela postestructuralista francesa, analiza el tema a partir del concepto

* Reseńa de la obra de Rosi Braidotti, Posthuman knowledge, Cambridge, Polity Press, 2019. 
de posthumanismo, que para ella implica un análisis detallado y crítico del humanismo moderno, el eurocentrismo y el antropocentrismo, todos éstos puestos en cuestión en lo que ella denomina convergencia posthumana, coyuntura que implica que "nosotros" (habitantes humanos y no humanos de este planeta en particular) estamos actualmente ubicados entre la Cuarta Revolución Industrial y la Sexta Extinción, entre el algoritmo diabólico y el acidificado mar azul profundo (Braidotti, 2019).

Es decir que nuestra condición actual responde al cruce entre la revolución tecnológica de la información y la crisis ambiental. Por eso Braidotti habla de subjetividad posthumana, de un modo de ser que es producto de dicho cruce y que constituye un cambio radical respecto del modelo de ser humano dibujado en la modernidad; no se trata de un sujeto estable y universal, sino múltiple y nómada -como ella lo califica retomando la filosofía nomádica de Deleuze y Guattari- que asume la paradoja de la euforia tecnológica y la desesperanza ambiental. En Braidotti, lo posthumano no constituye una distopía, sino un rasgo que define lo que hoy es la humanidad y, más precisamente, lo que deviene. La suya no es una visión nostálgica de un pasado asumido como algo mejor. Al contrario, Braidotti apuesta por las oportunidades que nos abre la condición posthumana para re-con-figurarnos, para redefinir al ser humano, negociar los términos de lo que cuenta como ser humano hoy y replantear el conocimiento social.

Braidotti inicia su exposición con la mencionada cuestión de lo posthumano, ampliamente desarrollada en un texto anterior (2013), para desplegar su análisis sobre la producción de conocimiento en la era posthumana, en particular, en el ámbito de las humanidades. El conocimiento posthumano sería fuertemente transdisciplinar, y acaso post-disciplinar ya que las tradicionales divisiones (historia, sociología, antropología, etcétera) darían paso a los "estudios" (latinoamericanos, chicanos, negros, feministas, decoloniales, de la ciencia y varios más).

Asimismo, el conocimiento posthumano se caracteriza por el reconocimiento del rol de actores in/no/post-humanos, la definición de objetos de estudio nuevos y una mayor creatividad conceptual; es decir, renueva la misión de las humanidades convencionales, cuestionando los hábitos de pensamiento antropocéntricos y ofreciéndoles conceptos más adecuados para lidiar con el ambiente ecológico, el continuo media-naturo-cultura y los otros no humanos (Braidotti, 2019). A nuestro modo de ver, una de las grandes aportaciones de los estudios (sociales/culturales) de la ciencia ha sido justamente la de introducir en el análisis teórico la participación de los actores no humanos, reconocer su agencia e incidencia en la articulación del mundo, y por lo tanto su inclusión en el "colectivo" (Latour, 2004), es decir, en el espacio político. 
Este cambio intelectual no sólo implica una redefinición de disciplinas, campos y/o líneas de investigación. Ni siquiera la introducción de lo no humano (orgánico o artificial) es condición suficiente para hablar de conocimiento posthumano. De acuerdo con Braidotti, esta transformación requiere abandonar los viejos marcos de análisis, los modos dominantes de pensamiento; ella lo plantea como desfamiliarización (2019), que -además de lo anterior- demanda un cambio cualitativo considerable en términos metodológicos y conceptuales, lo mismo que una ética colaborativa y relacional. Es decir, desde su perspectiva, el pensamiento en la era posthumana no puede ser concebido de manera individual, puesto que es un acto colectivo que no se circunscribe únicamente a la academia, ni siquiera es un atributo exclusivamente humano. En este punto, y en varios más en realidad, Braidotti coincide plenamente con Donna Haraway, quien habla de "pensamiento tentacular" y de "pensar-con" y quien reivindica igualmente la capacidad cognitiva de los animales no humanos (2016). Pensar es cosa del mundo, dice Braidotti (2019) para denotar el carácter mundano de la generación de conocimiento.

Quizá ese acto de des-humanizar y des-antropologizar el conocimiento es uno de los puntos centrales de este libro. Ya desde aquella otra obra (Lo posthumano, 2013), en la que Braidotti introdujo los elementos fundamentales de su teoría posthumana, dejó muy claro que esta era/condición posthumana implicaba el gran reto filosófico de des-montar el humanismo y el antropocentrismo, lo que en modo alguno significa caer en el relativismo o en el ecofascismo. No se sugiere siquiera el abandono completo de las ideas humanistas/ilustradas, ni se propone una posición humanófoba en absoluto. Simplemente, se apuesta por abandonar la arrogancia con la que la ciencia, las humanidades y las ciencias sociales se aproximan a la realidad bajo las falsas premisas del excepcionalismo humano o la naturaleza humana. Y más aún, el verdadero reto epistemológico que plantea Braidotti es no sólo el reconocimiento de la interdependencia entre especies, sino concebir a los no humanos como colaboradores de conocimiento. De nuevo ahí hay un puente muy claro con Haraway (2016).

Este libro representa no sólo una cartografía contemporánea del conocimiento social derivado de la convergencia posthumana -lo cual ya en sí mismo es muy útil para ubicar las corrientes, enfoques y temáticas del momento- sino una propuesta de gran calado sobre hacia dónde pueden ir las humanidades y sobre cómo aprender a pensar en clave posthumana. Vale la pena resaltar -sin ánimo de volver a los dualismos característicos de la modernidad- la doble, paradójica o ambivalente forma en que se produce el conocimiento posthumano. Braidotti señala que en el ámbito académico global hay, por un lado, lo que ella denomina ciencia mayor o real, puesta en práctica institucionalmente y altamente compatible con el imperativo económico neoliberal y, por el otro, una ciencia menor o nómada que, si bien es marginalizada, es ética y políticamente 
transformadora; esta última es por la que nuestra autora apuesta, lo que para ella representan las posthumanidades críticas y donde encuentra las posibilidades de una critica creativa, lo que implica dar cuenta de las formas de poder en el capitalismo avanzado y proporcionar las claves para configurar un futuro mejor, y así contrarrestar las narrativas distópicas del Antropoceno.

La de Braidotti no sólo es una reivindicación de la teoría (social), muy pertinente en un contexto de cierto desprecio social y/o institucional por el conocimiento teórico que ella justamente señala; la suya es también una defensa del pensamiento crítico en nombre de la potencia ética-política-que ella denomina afirmativa - que se requiere para hacer frente a la esquizoide convergencia posthumana (mezcla de euforia tecnológica y angustia medioambiental). La propuesta de Braidotti es narrar-nos en positivo, pensar conjuntamente en las posibilidades de, como humanidad, devenir algo a mejor. Por tanto, se trata de una defensa de las humanidades, pero no en la nostalgia del proyecto ilustrado, sino fundada en nuestra condición presente (ambivalente) y en la proyección o virtualización de lo que Haraway (2016) define como "mundos más vivibles".

Finalmente, desde la perspectiva encarnada y embebida del mundo de Braidotti -como buena feminista-, las (post)humanidades también podrían concebirse como ciencias experimentales. Es decir, el desarrollo teórico-conceptual está fundado en la experiencia efectiva de sujetos específicos y debe hacerse de manera colaborativa. De nuevo hay una coincidencia entre Braidotti (2019) y Haraway (2016), en el sentido de que para ambas la teoría no consiste en abstracciones (alejadas de la evidencia empírica), sino que es siempre corporal y situada.

\section{REFERENCIAS}

Braidotti, Rosi (2013). The Posthuman. Cambridge: Polity Press.

- (2019). Posthuman knowledge. Cambridge: Polity Press.

Haraway, Donna (2016). Staying with the Trouble: Making Kin in the Chthulucene. Durham: Duke University Press.

Latour, Bruno (2004). Politics of nature. How to bring the sciences into democracy. Cambridge: Harvard University Press. 


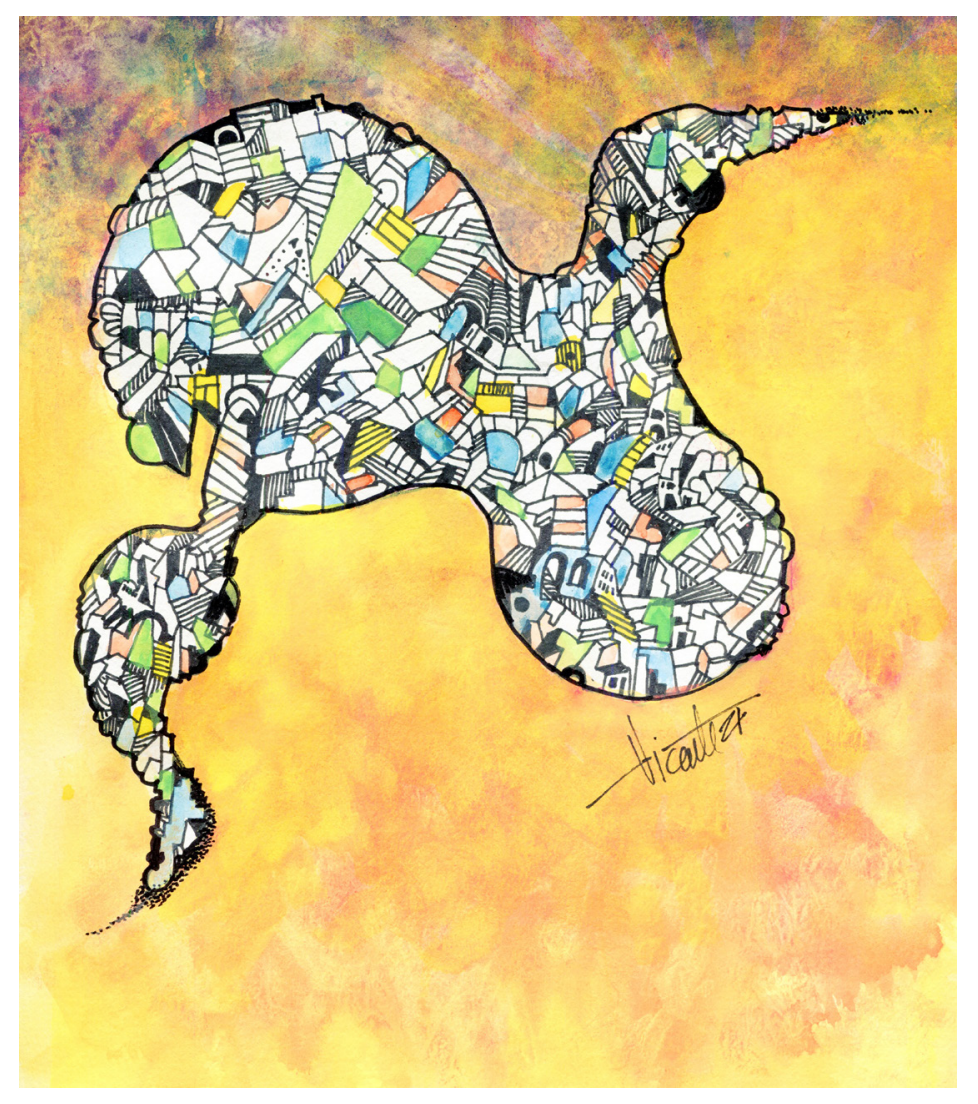


Vicente Guzmán Ríos | Wuhan 